\title{
Dental implants in patients with oral mucosal alterations: An update
}

\author{
$M^{a}$ Eugenia Candel-Marti ${ }^{1}$, Javier Ata-Ali ${ }^{2}$, David Peñarrocha-Oltra ${ }^{1}$, María Peñarrocha-Diago ${ }^{3}$, Jose . $^{2}$ \\ Bagán ${ }^{4}$
}

${ }^{1}$ DDS. Resident of the Master in Oral Surgery and Implantology. Valencia University Dental and Medical School

${ }^{2}$ DDS. Master in Oral Medicine and Surgery. Resident of the Master in Oral Surgery and Implantology. Valencia University Dental and Medical School

${ }^{3}$ Associate Professor of Oral Surgery. Valencia University Medical and dental School

${ }^{4}$ Chairman of Stomatology. Valencia University Medical and Dental School. Head of the Department of Stomatology. Valencia University General Hospital. Valencia (Spain)

Correspondence:

Cirugía Bucal. Clínicas Odontológicas,

Gascó Oliag 1,

46021 Valencia (Spain)

miguel.penarrocha@uv.es

\author{
Candel-Marti ME, Ata-Ali J, Peñarrocha-Oltra D, Peñarrocha-Diago \\ MA, Bagán JV. Dental implants in patients with oral mucosal alterations: \\ An update. Med Oral Patol Oral Cir Bucal. 2011 Sep 1;16 (6):e787-93. \\ http://www.medicinaoral.com/medoralfree01/v16i6/medoralv16i6p787.pdf

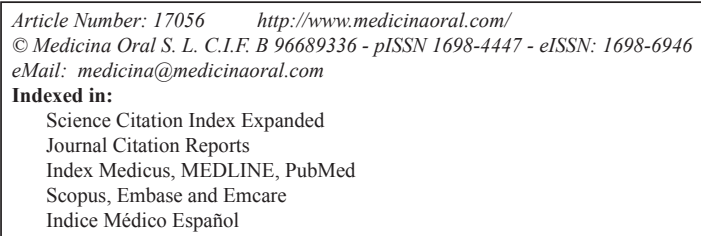

Received: $13 / 04 / 2010$

Accepted: 04/07/2010

\begin{abstract}
Objective: To determine whether a series of diseases of the oral mucosa - Sjögren syndrome, ectodermal dysplasia, epidermolysis bullosa and lichen planus - reduce the survival rate of dental implants.

Material and Method: A Medline search was carried out using the key words: "Sjögren syndrome", "ectodermal dysplasia", "epidermolysis bullosa", "lichen planus" and "dental implants", including those publications involving clinical series comprising more than one patient with the mentioned disorders and treated with dental implants, in the last 10 years.

Results: The study included three articles involving patients with Sjögren syndrome subjected to dental implant treatment, representing a total of 12 patients and 86 implants, with a mean pondered success rate of $86.33 \%$. As regards ectodermal dysplasia, we included 14 articles, of which 11 corresponded to clinical series, two were reviews and one constituted a survey of dental professionals. The percentage success rate of the implants varied between $35.7-100 \%$. In relation to epidermolysis bullosa, we included 6 articles corresponding to clinical series, with a total of 16 patients and 92 implants, and a success rate between $75-100 \%$. In the case of oral lichen planus we found only two articles corresponding to clinical case series, with a total of 5 patients and 14 implants, and an implant survival rate of $100 \%$.

Conclusions: Based on our review of the literature, dental implant rehabilitation in patients of this kind is seen to be a valid treatment option, with a high percentage success rate. Long-term patient follow-up is essential in order to periodically monitor the condition of the disease and of the implants.
\end{abstract}

Key words: Sjögren syndrome, oral lichen planus, epidermolysis bullosa, ectodermal dysplasia, dental implants 


\section{Introduction}

Dental implants are increasingly used to replace missing teeth, and offer a percentage success rate of close to $90-95 \%$ after 10 years. The literature contains many references to contraindications of implant treatment in patients with systemic diseases, though in some instances such contraindications appear to be only theoretical (1). Systemic diseases can affect the oral tissues, increasing the susceptibility to other pathologies or interfering with the healing processes. In addition, the management of such disorders with drugs or other therapies can affect the dental implants or the oral tissues supporting them (2).

While some systemic diseases and oral mucosal disorders commonly have been regarded as contraindications for the placement of implants, the benefits of such treatment in these patients sometimes outweigh the risks.

The present study examines whether these alterations of the oral mucosa, such as Sjögren syndrome, ectodermal dysplasia, epidermolysis bullosa and oral lichen planus (OLP), are able to directly influence dental implant survival. To this effect, a literature review has been made to assess the possible influence of these oral mucosal disorders upon implant stability and failure.

Sjögren syndrome is a chronic systemic autoimmune disease affecting the exocrine glands, particularly the salivary and lacrimal glands, with the development of hyposialia that adversely affects patient quality of life (3). Ectodermal dysplasia in turn comprises a group of genetic disorders including congenital defects of two or more ectodermal structures such as the skin, hair, nails, nerve cells, sweat glands and parts of the eyes and ears (4-7). These patients present severe oligodontia or anodontia - dental implants being the treatment of choice in both adults and in patients during the growth phase $(8,9)$. Hereditary epidermolysis bullosa comprises a group of hereditary diseases of the skin and mucosal membranes, characterized by the development of blisters and vesicles in response to minimum friction or trauma (10-17). Lastly, lichen planus is a chronic inflammatory disease of the skin and mucosas that evolves in the form of outbreaks or flare-ups (18).

A Medline search was carried out using the key words: "Sjögren syndrome", "ectodermal dysplasia", "epidermolysis bullosa", "lichen planus" and "dental implants", including those publications involving clinical series comprising more than one patient with the mentioned disorders and treated with dental implants, in the last 10 years. The study finally included four articles on Sjögren syndrome, 15 articles on ectodermal dysplasia, and 8 articles on epidermolysis bullosa and oral lichen planus.

\section{Sjögren Syndrome}

Sjögren syndrome is a chronic systemic autoimmune disease affecting the exocrine glands, particularly the salivary and lacrimal glands, and characterized by the appearance of a lymphocytic inflammatory infiltrate that interferes with gland function. There are two clinical forms of the syndrome, a primary presentation characterized by keratoconjunctivitis sicca and hyposialia, and a secondary presentation which in addition to these two clinical signs also presents connective tissue disease - usually in the form of rheumatoid arthritis or systemic lupus erythematosus. Sjögren syndrome is one of the three most frequent autoimmune disorders, together with systemic lupus erythematosus and systemic sclerosis. It affects $0.5-3 \%$ of the population, and is more prevalent in women than in men (9:1 proportion) (3).

Patients with Sjögren syndrome have speech, chewing and swallowing difficulties, with dry mouth sensation or xerostomia - this being the manifestation with the greatest impact upon patient quality of life. The disease is also characterized by taste alterations, and burning sensation or pain in the salivary glands related with the ingestion of food. The clinical signs in turn comprise hyposialia, cracked, dry and desquamative lips, and a dry, dirty, erythematous and cracked tongue. Also very common is the association of angle cheilitis, rampant caries in atypical locations, occlusal wear or attrition, gland swelling, mucositis and oral ulcerations. Chronic erythematous candidiasis due to Candida albicans is seen in $70-80 \%$ of the patients, affecting the tongue, palate and lip commissures (3).

Patients with Sjögren syndrome and dental implants Patients with Sjögren syndrome suffer xerostomia, which often causes them to reject wearing conventional removable dentures, due to poor retention and severe difficulties associated with their presence in the mouth. It has been proposed that these patients may benefit from prostheses with artificial saliva reservoirs, which could reduce the unpleasant sensation produced by the removable dentures (19). In any case, treatment with dental implants is presently the most widely accepted solution.

Three studies involving implants in patients with Sjögren syndrome with long-term follow-up have been found in the literature (Table 1). Payne et al. (20) placed 26 implants in three patients, with an $88.4 \%$ success rate. Isidor et al. (19) reported an $84 \%$ success rate after four years of follow-up in 8 women with implantretained removable dentures. After two years, the patients reported a high degree of satisfaction. Binon (21) controlled one patient with Sjögren syndrome during 13 years, rehabilitated with a fixed prosthesis over 6 implants, and reported a $100 \%$ success rate.

In patients with secondary Sjögren syndrome and advanced rheumatoid arthritis, careful evaluation is required of their degree of manual dexterity, considering the movement limitations of these patients, in order to ascertain that they are able to properly maintain oral hygiene after treatment with prostheses over implants. 
Table 1. Published series of implants in patients with Sjögren syndrome.

\begin{tabular}{|c|c|c|c|c|c|c|}
\hline AUTHOR & PATIENTS & AGE & SEX & IMPLANTS & \% SUCCESS & FOLLOW-UP \\
\hline Payne 1997 & 3 & $38-40$ & Women & 26 & 88.4 & 2 years \\
\hline Isidor 1999 & 8 & $53-70$ & Women & 54 & 84 & 4 years \\
\hline Binon 2005 & 1 & 67 & Male & 6 & 100 & 13 years \\
\hline
\end{tabular}

The severity of Sjögren syndrome and the medical complications of the patient must be evaluated before recommending the routine placement of implants (20).

\section{Ectodermal Dysplasia}

Anhidrotic ectodermal dysplasia comprises a group of genetic disorders including congenital defects of two or more ectodermal structures such as the skin, hair, nails, nerve cells, sweat glands and parts of the eyes and ears (4-7).

The disease is relatively rare, with a frequency of between 1:10,000 and 1:100,000 live births, and is more common in males than in females. Other authors report an incidence of 1-7:100,000 (8). In most cases the disorder shows a recessive autosomal hereditary pattern, though dominant autosomal or chromosome X-linked forms are also observed (2).

The diagnosis of patients with ectodermal dysplasia is fundamentally based on the clinical history (ungual dystrophy, hypotrichosis, anodontia, oligodontia, hypodontia); a skin biopsy in cases with perspiration alterations (reduction in the number of pilosebaceous units and sweat glands); the presence of fine and thin hair; a panoramic X-ray study (revealing dental morphological alterations and agenesis); and a molecular genetic analysis.

At oral cavity level, ectodermal dysplasia is characterized by the observation of anodontia and hypodontia of the temporal and permanent dentition, impacted teeth, pin-type dental malformations, enamel hypoplasia, multiples diastemas and under-developed alveolar ridges. These problems give rise to aesthetic and functional problems, and difficulties for supporting conventional prostheses (4-8).

In recent years treatment with dental implants has been offered for patients with ectodermal dysplasia, since they are compatible with correct development of the maxillofacial skeletal structures and improve prosthetic stability. However, it may prove difficult to achieve adequate primary stability with the conventional techniques - bone grafts or implants in abutments being required in such situations $(4,8,22)$.

Ectodermal dysplasia and dental implants

Age at placement of implants and growth

Due to the anatomical characteristics of patients with ectodermal dysplasia who present severe oligodontia or anodontia, dental implant placement is the treatment of choice both in adults and in patients in the growth phase. This improves both aesthetics and function, with improved patient quality of life $(8,9)$.

In growing patients, conventional prostheses may have a negative effect (8), with an adverse psychological impact for the patients (5). In these subjects, early treatment with dental implants can offer the possibility of correct development of speech, chewing and swallowing, allowing normal facial and temporomandibular joint development, and improving patient self-esteem (5). In the consensus conference on the dental treatment of children with ectodermal dysplasia, held in Sweden in 1998, treatment with implants was accepted in patients from 6-7 years of age.

The main problem in these patients is the change in the position and angulation of the implants, as well as their ankylosis (4-6, 23). When treating children with dental implants, due consideration is required of both the patient growth stage and the number and location of missing teeth $(4,5,23)$. If the patient is partially edentulous, the existing teeth stimulate vertical growth of the alveolar ridge, resulting in implant ankylosis. For this reason Imirzalioglu et al. (5) recommend the postponement of implant placement to 12 years of age in partially edentulous patients, while in totally edentulous children placement can be indicated from the age of three years $(5,6)$.

As regards the location of the implants, their interforaminal placement is recommended by most authors (4-6), due to the "v"-form growth of the mandible, which results in minimal changes in the position of the implants. In the upper maxilla the age at placement is postponed to 17 years, when growth has practically ceased $(4,6)$. Guckes et al. (6) recommends interconsultation with the orthodontist to ensure that growth has effectively stopped.

On the other hand, Percinoto et al. (24) do not recommend treatment in growing children, except in very severe cases of ectodermal dysplasia.

Type of prosthesis

Most authors use fixed or removable dentures, placed 3-4 months after implant placement in the mandible, and 5-6 months after implant placement in the upper maxilla. Guckes et al. (6) recommend overdentures in 
growing children, since the prosthesis is easier to adjust as a consequence of the continuous wear attributable to growth and the occlusal changes.

Grafts and ectodermal dysplasia

The main problem in patients of this kind is the limited amount of bone, particularly in the upper arch.

In the present review it was found that when patients presented scant bone volume, bone grafting and/or sinus lift procedures were carried out $(4,5,8)$ without penalizing percentage success. Imirzalioglu et al. (5) recommended treatment with implants as soon as possible in order to prevent further bone loss over time and the need for bone grafting. These authors presented two clinical cases: bone grafting and implant placement were carried out in one of them (a 14-year-old boy), while orthognathic surgery and implant placement were carried out in the other (a 17-year-old boy) - with correct functioning in both patients.

Garagiola et al. (25), after comparing the success of guided bone regeneration with bone grafting plus membrane placement in patients with ectodermal dysplasia, concluded that both techniques offer the same degree of osteointegration.

\section{Percentage success}

The implant success criteria used in patients with ectodermal dysplasia were the absence of symptoms in the form of periimplantitis, bleeding or suppuration, a high probe depth, inflammation and mobility $(4,6)$.

The percentage success of implant treatment ranged from 35.7-95\% (Table 2). Bergendal et al. (9) obtained a $35.7 \%$ success rate after placing 33 implants in 21 patients between 5-12 years of age. These authors attribued the low success rate to the small size of the mouth and scant bone volume in these patients.

The success rates in the upper maxilla were lower than in the mandible. In a series of 14 patients with ectodermal dysplasia, Sweeney et al. (4) carried out upper maxillary rehabilitation in patients between 17-20 years of age, and mandibular rehabilitation in those between 1220 years of age - with a success rate of $80 \%$ in the maxilla and $91.3 \%$ in the mandible. In turn, Guckes et al. (6), after treating 51 patients with 264 implants, concluded that implant placement in the upper maxilla has a 2.8fold greater probability of failure than in the mandible. In a review published by Yap et al. (7), the percentage success rate was found to be $88.5-97.6 \%$, and tended to decrease when implants were placed in patients under 18 years of age. Similar results were reported by Guckes et al. (6), who found the percentage success rate in patients under 18 years of age to be $85-87 \%$, versus $95 \%$ in those over 18 years of age.

\section{Epidermolysis Bullosa}

Hereditary epidermolysis bullosa comprises a group of hereditary diseases of the skin and mucosal membranes, with the development of blisters and vesicles in response to minimum friction or trauma. The disorder in turn is classified into three major categories (simple, junctional and dystrophic) according to the level of tissue rupture following trauma, and 25 subtypes (10-17). The oral manifestations of epidermolysis bullosa are repeated blistering, the formation of scars, limitation of oral aperture, ankyloglossia, disappearance of the oral and vestibular sulci, perioral stenosis, severe periodontal disease and bone reabsorption, atrophy of the upper maxilla with mandibular prognathism, an increased mandibular angle, and a predisposition to oral carcinoma. Routine brushing can produce blistering of the oral mucosa (10-17). In some cases rampant caries are observed in combination with hypoplastic dental enamel and poor oral hygiene (25).

Epidermolysis bullosa and dental implants

Totally edentulous patients with epidermolysis bullosa are candidates for dental implant treatment, since conventional prostheses cause mucosal irritation and tissue friction, with blistering and tissue rupture (12). Our re-

Table 2. Published series of implants in patients with ectodermal dysplasia.

\begin{tabular}{|l|c|c|c|}
\hline \multicolumn{1}{|c|}{ AUTHOR } & PATIENTS & IMPLANTS & \% SUCCESS \\
\hline Kargul et al. 2001 & 3 & - & 100 \\
\hline Imirzaliogli et al. 2002 & 3 & 4 & 100 \\
\hline Guckes et al. 2002 & 51 & 264 & 91 mandible 76 maxilla \\
\hline Oczakir et al. 2005 & 4 & - & 100 \\
\hline Sweeney et al. 2005 & 14 & 61 & 67.2 \\
\hline Garagiola et al. 2008 & 33 & 186 & 100 \\
\hline Bergendal et al. 2008 & 21 & 33 & 35.7 \\
\hline Gill et al. 2008 & - & - & - \\
\hline Carmichael et al. 2008 & - & - & - \\
\hline Fotso et al. 2009 & 2 & - & 100 \\
\hline Kirmeier et al. 2009 & 2 & 28 & 100 \\
\hline
\end{tabular}


Table 3. Published series of implants in patients with epidermolysis bullosa.

\begin{tabular}{|l|c|c|c|c|c|c|}
\hline \multicolumn{1}{|c|}{ AUTHOR } & PATIENTS & AGE & IMPLANTS & $\begin{array}{c}\text { FOLLOW-UP } \\
\text { (months) }\end{array}$ & \% SUCCESS & PROSTHESIS \\
\hline Peñarrocha M, 2007 & 3 & $29-49$ & 27 & $12-60$ & 97.7 & Fixed \\
\hline Peñarrocha M, 2000 & 4 & $26-35$ & 15 & $12-58$ & 100 & Overdenture \\
\hline Peñarrocha M, 2007 & 6 & $23-44$ & 38 & $12-108$ & 97.9 & Fixed Overdenture \\
\hline Lee H, 2007 & 1 & 29 & 8 & - & 75 & Fixed \\
\hline Larrazabal C, 2009 & 1 & 52 & 2 & 12 & 100 & Fixed \\
\hline Oliveira, 2010 & 1 & 13 & 2 & 48 & 100 & Fixed \\
\hline
\end{tabular}

Table 4. Published series of implants in patients with oral lichen planus - all with $100 \%$ success rates after the stated period of follow-up.

\begin{tabular}{|c|c|c|c|c|c|c|}
\hline AUTHOR & PATIENTS & AGE & IMPLANTS & $\begin{array}{c}\text { FOLLOW-UP } \\
\text { (months) }\end{array}$ & PROSTHESIS & TYPE \\
\hline Esposito, 2003 & 2 & 72 and 78 & 4 & 21 & Overdenture & Erosive \\
\hline Reichart, 2006 & 3 & $63-79$ & 10 & 36 & Unit and bridges & Reticular and atrophic \\
\hline
\end{tabular}

view of the literature yielded 6 clinical series of patients with epidermolysis bullosa treated with implants. In these studies, 16 patients were rehabilitated with a total of 92 implants and a success rate of $75-100 \%$ (Table 3). The intervention in patients of this kind is complicated due to the formation of bleeding blisters in response to minimal trauma such as incision or flap raising (10-17). In addition, if implants are placed we have the added problem of the need for irrigation with saline solution, which must be aspirated - and aspirator contact with the mucosal membranes produces blistering.

Surgery is carried out under local anesthesia in most cases (10-13), injecting the solution slowly in order to avoid tissue damage, since general anesthesia poses the added problem of possible ulcerations caused by intubation. However, Lee et al. (14) have carried out surgery under general anesthesia.

In patients with important upper maxillary atrophy, the implants are placed using osteotomes, since conventional drilling could destroy the residual bony process and thus reduce primary retention of the implant. Drilling and irrigation are only used to create a minimum aperture in the residual process to allow access with small-diameter osteotomes (10-13). In contrast, in the mandible, surgical drills are required with minimum irrigation and placing the aspirator in contact with bone instead of soft tissues. Even so, mucosal blistering appears at mandibular level (10-13). During surgery continuous patient lip lubrication is required, taking care with lateral traction upon the cheek, in order to avoid wounds and blisters (10-13).

According to the reviewed literature, in totally edentulous patients the implants were placed in the sector anterior, due to problems of accessibility caused by the patient microstomia.
The follow-up period ranged from 12-108 months, and 13 patients $(86.7 \%)$ developed oral ulcerations in areas of friction with the prostheses. In no cases were periimplant mucosal alterations or blisters around the implant observed.

The quality of life of these patients improved considerably, and they were able to chew and swallow correctly. Peñarrocha et al. (11) compared the degree of satisfaction among patients rehabilitated with fixed prostheses versus those rehabilitated with overdentures, recording a score of 9.6 and 8.8 , respectively.

All the authors concluded that the use of dental implants in patients with epidermolysis bullosa is appropriate, with a high success rate, and offering adequate support for the prosthesis $(10-12,14,18)$ (Table 3).

\section{Oral Lichen Planus}

Oral lichen planus (OLP) is a chronic inflammatory disease of the skin and mucosal membranes that evolves in the form of outbreaks or flare-ups. It affects $0.2-1.9 \%$ of the population and is more common in women. The age range of the affected patients is 30-70 years. The etiology underlying OLP is not clear (26). Clinically, the disease is characterized by papular and reticular lesions that tend to alternate with areas of erythema and atrophy, and exhibit a certain dynamism. In the oral mucosa, lichen planus can adopt varied clinical forms (26).

Silverman et al. (27) proposed dividing the disease into reticular, atrophic and erosive forms, while Bagán et al. (28) have simplified classification by considering two forms: a) exclusively white reticular lesions, and b) atrophic or ulcerative lesions with or without reticular lesions. These latter forms produce symptoms such as itching or burning sensation.

Mignogma et al. (29) applied a patient monitoring pro- 
tocol involving visits every four months during 12 years in 45 patients with oral lichen planus who developed 117 malignant neoplastic events. With this protocol they detected $94.9 \%$ of the carcinomas in an early stage (intraepithelial or microinvasive) - achieving survival rates after 3 and 5 years of $100 \%$ and $96.7 \%$, respectively. The authors recommended control of these patients twice a year.

\section{Oral lichen planus and dental implants}

The great majority of contraindications for the placement of dental implants are related to the quantity and quality of the alveolar bone, and very few are related to the gums and the alveolar mucosa (30). It has been suggested that in these patients the capacity of the epithelium to adhere to the titanium surface of the implant is altered (31).

Despite the generalized use of dental implants, the literature documents only 5 cases of implant placement in patients with oral lichen planus $(31,32)$. These 5 patients received a total of 14 implants, with a success rate of 100\% (Table 4).

Esposito et al. (31) found that the placement of dental implants for the fitting of overdentures reduced the incidence of erosive lesions, and increased patient comfort and oral function. These patients require special care such as removal of the prosthesis during the two weeks after implant placement, and the application of topical corticosteroids.

It should be remembered that oral lichen planus is a precancerous condition, and that although the malignant transformation rate generally does not exceed $1 \%$ (32), the possibility of malignization must be taken into account, monitoring both the lesions derived from OLP and the condition of the dental implants.

Based on our review of the literature, rehabilitation with implants in patients of this kind is a valid treatment option, with a success rate of $86.33 \%$ in patients with $\mathrm{Sjö-}$ gren syndrome, $35.2-100 \%$ in patients with ectodermal dysplasia, $96.75 \%$ in patients with epidermolysis bullosa, and $100 \%$ in patients with OLP.

Long-term controls are essential to ensure adequate follow-up of the disease and of the dental implants.

\section{References}

References with links to Crossref - DOI

1. Scully C, Hobkirk J, Dios PD. Dental endosseous implants in the medically compromised patient. J Oral Rehabil. 2007;34:590-9.

2. Bornstein MM, Cionca N, Mombelli A. Systemic conditions and treatments as risks for implant therapy. Int J Oral Maxillofac Implants. 2009;24 Suppl:12-27.

3. Margaix-Muñoz M, Bagán JV, Poveda R, Jiménez Y, Sarrión G. Sjögren's syndrome of the oral cavity. Review and update. Med Oral Patol Oral Cir Bucal. 2009;14:E325-30.

4. Sweeney IP, Ferguson JW, Heggie AA, Lucas JO. Treatment outcomes for adolescent ectodermal dysplasia patients treated with dental implants. Int J Paediatr Dent. 2005;15:241-8.

5. Imirzalioglu P, Uckan S, Haydar SG. Surgical and prosthodontic treatment alternatives for children and adolescents with ectodermal dysplasia: a clinical report. J Prosthet Dent. 2002;88:569-72.
6. Guckes AD, Scurria MS, King TS, McCarthy GR, Brahim JS. Prospective clinical trial of dental implants in persons with ectodermal dysplasia. J Prosthet Dent. 2002;88:21-5.

7. Yap AK, Klineberg I. Dental implants in patients with ectodermal dysplasia and tooth agenesis: a critical review of the literature. Int J Prosthodont. 2009;22:268-76.

8. Kirmeier R, Gluhak C, Marada P, Wegscheider WA, Eskici A, Jakse N. Oral rehabilitation of adult twins with severe lack of bone due to hypohidrotic ectodermal dysplasia--a 12-month follow-up. J Oral Maxillofac Surg. 2009;67:189-94.

9. Bergendal B, Ekman A, Nilsson P. Implant failure in young children with ectodermal dysplasia: a retrospective evaluation of use and outcome of dental implant treatment in children in Sweden. Int J Oral Maxillofac Implants. 2008;23:520-4.

10. Penarrocha M, Rambla J, Balaguer J, Serrano C, Silvestre J, Bagán JV. Complete fixed prostheses over implants in patients with oral epidermolysis bullosa. J Oral Maxillofac Surg. 2007;65:103-6.

11. Peñarrocha M, Larrazábal C, Balaguer J, Serrano C, Silvestre J, Bagán JV. Restoration with implants in patients with recessive dystrophic epidermolysis bullosa and patient satisfaction with the implant-supported superstructure. Int J Oral Maxillofac Implants. 2007;22:651-5.

12. Peñarrocha-Diago M, Serrano C, Sanchis JM, Silvestre FJ, Bagán JV. Placement of endosseous implants in patients with oral epidermolysis bullosa. Oral Surg Oral Med Oral Pathol Oral Radiol Endod. 2000;90:587-90.

13. Serrano-Martínez MC, Bagán JV, Silvestre FJ, Viguer MT. Oral lesions in recessive dystrophic epidermolysis bullosa. Oral Dis. 2003;9:264-8.

14. Lee H, Al Mardini M, Ercoli C, Smith MN. Oral rehabilitation of a completely edentulous epidermolysis bullosa patient with an implant-supported prosthesis: a clinical report. J Prosthet Dent. 2007;97:65-9.

15. Larrazabal-Morón C, Boronat-López A, Peñarrocha-Diago M, Peñarrocha-Diago M. Oral rehabilitation with bone graft and simultaneous dental implants in a patient with epidermolysis bullosa: a clinical case report. J Oral Maxillofac Surg. 2009;67:1499-502.

16. Oliveira MA, Ortega KL, Martins FM, Maluf PS, Magalhães MG. Recessive dystrophic epidermolysis bullosa--oral rehabilitation using stereolithography and immediate endosseous implants. Spec Care Dentist. 2010;30:23-6.

17. Serrano Martínez C, Silvestre Donat FJ, Bagán Sebastián JV, Peñarrocha Diago M, Alió Sanz JJ. Hereditary epidermolysis bullosa. Dental management of three cases. Med Oral. 2001;6:48-56.

18. Bermejo-Fenoll A, López-Jornet P, Camacho-Alonso F, SauraIngles A, Panchon-Ruiz A. Morphometric analysis of the dorsum linguae in patients with Oral Lichen Planus. Med Oral Patol Oral Cir Bucal. 2009;14:e388-92.

19. Isidor F, Brøndum K, Hansen HJ, Jensen J, Sindet-Pedersen S. Outcome of treatment with implant-retained dental prostheses in patients with Sjögren syndrome. Int J Oral Maxillofac Implants. 1999;14:736-43.

20. Payne AG, Lownie JF, Van Der Linden WJ. Implant-supported prostheses in patients with Sjögren's syndrome: a clinical report on three patients. Int J Oral Maxillofac Implants. 1997;12:679-85.

21. Binon PP. Thirteen-year follow-up of a mandibular implant-supported fixed complete denture in a patient with Sjogren's syndrome: a clinical report. J Prosthet Dent. 2005;94:409-13.

22. Fotso J, Hugentobler M, Kiliaridis S, Richter M. [Anhidrotic ectodermal dysplasia. Rehabilitation]. Rev Stomatol Chir Maxillofac. 2009;110:50-4.

23. Sharma AB, Vargervik K. Using implants for the growing child. J Calif Dent Assoc. 2006;34:719-24.

24. Percinoto C, Vieira AE, Barbieri CM, Melhado FL, Moreira KS. Use of dental implants in children: a literature review. Quintessence Int. 2001;32:381-3.

25. Garagiola U, Maiorana C, Ghiglione V, Marzo G, Santoro F, Szabò $\mathrm{G}$. Osseointegration and guided bone regeneration in ectodermal dysplasia patients. J Craniofac Surg. 2007;18:1296-304. 
26. Scully C, Carrozzo M. Oral mucosal disease: Lichen planus. Br J Oral Maxillofac Surg. 2008;46:15-21.

27. Silverman S Jr, Gorsky M, Lozada-Nur F. A prospective followup study of 570 patients with oral lichen planus: persistence, remission, and malignant association. Oral Surg Oral Med Oral Pathol. 1985;60:30-4.

28. Bagán-Sebastián JV, Milián-Masanet MA, Peñarrocha-Diago M, Jiménez Y. A clinical study of 205 patients with oral lichen planus. J Oral Maxillofac Surg. 1992;50:116-8.

29. Mignogna MD, Fedele S, Lo Russo L. Dysplasia/neoplasia surveillance in oral lichen planus patients: a description of clinical criteria adopted at a single centre and their impact on prognosis. Oral Oncol. 2006;42:819-24.

30. Reichart PA. Oral lichen planus and dental implants. Report of 3 cases. Int J Oral Maxillofac Surg. 2006;35:237-40.

31. Esposito SJ, Camisa C, Morgan M. Implant retained overdentures for two patients with severe lichen planus: a clinical report. J Prosthet Dent. 2003;89:6-10.

32. Cortés-Ramírez DA, Gainza-Cirauqui ML, Echebarria-Goikouria MA, Aguirre-Urizar JM. Oral lichenoid disease as a premalignant condition: the controversies and the unknown. Med Oral Patol Oral Cir Bucal. 2009;14:E118-22. 